\title{
Providing Support Services for Medical Students on a Rural Regional Medical Campus
}

\author{
Lucy Kollhoff • Michael Kollhoff • William Cathcart-Rake
}

Published online: 18 February 2015

(C) The Author(s) 2015. This article is published with open access at Springerlink.com

\begin{abstract}
One hundred fourteen regional medical campuses (RMCs) are currently recognized by the American Association of Medical Colleges (AAMC). This large number has been the result of the recognized need to train more physicians to serve a growing population and to address the uneven distribution of physicians in North America. Several RMCs were established in less populated regions, with the expectation that many trainees would eventually choose to practice in more rural locales. The Liaison Committee on Medical Education (LCME) mandates that a RMC must provide an academic program for its medical students equivalent to that provided on the main campus and must also provide equivalent support services for medical students. The small, rural RMC of the University of Kansas School of Medicine (KUSM) in Salina was established in 2011 with a mission to train more physicians who would serve rural Kansas. This RMC has successfully implemented an academic program. The authors report how the Salina RMC has satisfied the student support services described in the new standards for accreditation for July 2015.
\end{abstract}

Keywords Student support services $\cdot$ Regional medical campuses

\section{Introduction}

In 2006, the American Association of Medical Colleges (AAMC) called for a $30 \%$ increase from the 2002 level in the US medical school enrollment over the ensuing 10 years

L. Kollhoff $\cdot$ M. Kollhoff $\cdot$ W. Cathcart-Rake $(\triangle)$

University of Kansas School of Medicine-Salina, 400 South Santa

Fe, Salina, KS 67401, USA

e-mail: wcathcart-rake@kumc.edu to meet future physician needs [1]. They recommended this goal be met by "increasing enrollment at existing medical schools as well as by establishing new medical schools." In 2013, the AAMC reported a $21.6 \%$ increase in medical school enrollment and predicted that first-year medical school matriculation in 2018-2019 would come close to reaching the $30 \%$ targeted increase called for in 2006 [2]. The increase in medical school enrollment is largely due to increases in class size for the 125 schools that were accredited by the Liaison Committee on Medical Education in 2002 (accounting for two thirds of the increase). The remaining increase is the result of opening 16 new allopathic medical schools, the expansion of branch campuses, and the opening of new regional or branch campuses.

The AAMC's Group on Regional Medical Campuses (GRMC) currently lists 57 medical schools with RMCs and a total of 114 regional medical campuses (RMC) in the USA and Canada [3]. By definition, a RMC is separate from the main campus but does not receive independent accreditation from the LCME. Cheifetz et al. have proposed four different classification models for RMCs: (1) basic science (typically years 1 and 2), (2) clinical (clerkships in years 3 and 4), (3) longitudinal/ distributed (basic science and/or clinical experiences spanning a period greater than 12 weeks in one or more courses of study or core areas; learners must be continuously assigned to the site over repeated cycles), and (4) combined (basic science and clinical years offered in some combination-for example, years 1,2 , and 3 in whole or part; years 2, 3, and 4; or all 4 years) [4]. Regardless of the model chosen to deliver the curriculum or the location of the RMC, the main campus must ensure that in addition to providing an equivalent academic program, the RMC must also provide equivalent student support services.

In 2011, a rural branch campus of the University of Kansas School of Medicine (KUSM) was established in Salina, KS. Salina is the smallest city, and one of only 16 communities in the USA or Canada, to host a combined (years 1,2,3, and 4) $\mathrm{RMC}[3,5]$. The important elements in the development of the 
Salina RMC have been previously reported [6]. Salina is a city of approximately 48,000 residents in the predominately agricultural region of north central Kansas, $175 \mathrm{mi}$. west of the main campus in Kansas City, KS (metropolitan statistical area population of 880,000 residents) and $90 \mathrm{mi}$. north of the KUSM RMC in Wichita, KS (metropolitan statistical area population of 386,000 residents). The health care needs of the Salina community and surrounding rural area are served by Salina Regional Health Center (SRHC), a progressive regional hospital (212 staffed beds) providing a full range of services. SRHC is a major stakeholder in the establishment of KUSM-Salina, providing not only financial support but also providing student support services and clinical experiences for medical students and residents.

The mission of KUSM-Salina is to train a small cohort (eight students in each class) of medical students in a rural environment, expecting that many will eventually choose a primary care practice in rural Kansas. The first class of eight students (Class of 2015) started classes in July 2011, and with the matriculation of a fourth class of medical students in July 2014, the Salina campus reached its full complement of 32 students. Thirty of the first 32 students are Kansas residents, and 29 of the students came from rural communities with populations smaller than Salina.

Despite its relatively brief history, the Salina campus has been successful in implementing the medical school curriculum designed by the main campus. Salina student performance on basic science course summative exams in years 1 and 2, NBME subject exams in year 3, and USMLE step I (mean score $=223$ for the classes of 2015 and 2016) and step II CK exams (mean score $=242$ for the class of 2015) has been equivalent to the performance of the students in Kansas City and Wichita. Salina students are satisfied with the delivery of the basic science curriculum during years 1 and 2 and with the breadth and depth of their clinical experiences in years 3 and 4. The main campus tracks patient encounters by all medical students during required clinical clerkships in year 3. Salina students see as many or more patients and disease processes as their peers in Kansas City and Wichita. Additionally, the KUSM-Salina campus has effectively provided the necessary student support services. A survey of students on all three campuses regarding support services reveals that Salina students are satisfied with the quality of these services [7].

In the fall of 2013, the LCME conducted an accreditation survey of the main campus of KUSM in Kansas City, KS, and its two RMCs in Wichita and Salina. After review of the survey team's report, the LCME voted to continue accreditation of the medical education program at KUSM for an 8-year term. The committee complemented KUSM for establishing innovative educational programs to address the state's needs for rural physicians and listed no deficiencies in the provision of support services for the medical students on the Salina campus.
This paper will review how a rural RMC provides the LCME-required support services outlined in the document Functions and Structures of a Medical School, which become effective July 1, 2015 [8]. Similar reports regarding provision of student support services by RMCs have not been found. Seventeen different elements dealing with student services have been identified and a short summary describes how each of these is being addressed on the Salina campus. The policies and procedures developed by the Salina RMC may be useful for other medical schools establishing rural branch campuses.

\section{LCME-Required Student Support Services (per New Standards and Elements Effective July 1, 2015)}

1. Community of Scholars/Research Opportunities (Element 3.2)-"A medical education program is conducted in an environment that fosters the intellectual challenge and spirit of inquiry appropriate to a community of scholars and provides sufficient opportunities, encouragement, and support for medical student participation in research and other scholarly activities of its faculty."

Although there is no basic science research being conducted on the rural Salina RMC, Salina students frequently communicate with the basic scientists on the main campus in Kansas City and have the opportunity to participate in basic science research projects on that campus during the summer between their first and second years of medical school and during elective time during their fourth year of medical school. Salina students also have the opportunity, and have taken the opportunity, to participate in educational and clinical research projects sponsored by faculty members on the main campus and on the Salina campus. Students are encouraged to prepare scholarly reports for oral presentation, poster sessions, and publication. To date, 11 Salina students have participated in the summer Primary Care Practice and Research Program sponsored by the Department of Family Medicine on the main campus. During the summer between years 1 and 2, students in this program work with a rural community primary care physician and also collect data about patient health, preventive health care, health behavior, and rural primary care practice in Kansas. Additionally, one student has participated in a clinical research project in Salina and reported her results at a regional forum, and one student has presented a poster at an international meeting describing an immunology study guide he developed.

2. Security, Student Safety, and Disaster Preparedness (Element 5.7) - "A medical school ensures that adequate security systems are in place at all locations and publishes policies and procedures to ensure student safety and address emergency and disaster preparedness." 
Security, student safety, and disaster preparedness are a high priority on the Salina rural RMC. Safety and security measures on the Salina campus were initiated after extensive consultation with officials on the Kansas City campus. The local campus has published guidelines regarding safety practices which are reviewed with students during yearly orientation sessions. Salina-specific policies and procedures regarding campus security and safety, and inclement and dangerous weather are readily accessible on the KUSM-Salina website. The medical education building is located on the Salina Regional Health Center (SRHC) campus, which provides 24hour security services. Students may call for a security service escort to accompany them while walking from the medical education building to their vehicles in a nearby parking lot. There are emergency phones on each floor of the medical education building. Fire drills are coordinated with SRHC. Severe weather warnings are announced by SRHC, and the medical education building basement is a tornado shelter. KUSM also subscribes to the Rave ${ }^{\circledR}$ mobile safety system. Students are automatically enrolled to receive emergency text messages and/or e-mails from campus officials.

3. Library Resources/Staff (Element 5.8)_-“A medical school provides ready access to well-maintained library resources sufficient in breadth of holdings and technology to support its educational and other missions."

The rural RMC maintains a small collection of frequently used textbooks and study guides in the local medical education building. Students have 24/7 high-speed internet access to the comprehensive digital holdings, including multiple recommended textbooks, in Dykes Health Sciences Library on the main campus and may contact a librarian on the main campus for assistance in securing reference materials. Students can electronically request additional published resources and reserve such material not held by Dykes library. Local library assistance is provided by the campus medical education instruction specialist.

4. Information Technology Resources/Staff (Element 5.9) "A medical school provides access to well-maintained information technology resources..."

The Salina RMC relies heavily on the main campus information technology (IT) resource center and staff to provide IT support. The Salina medical education instruction specialist provides IT services on weekdays and serves as a liaison with the main campus IT staff. The local campus is dependent on reliable connections via interactive television (ITV) for delivery of educational content, shared academic events, course reviews, staff training, and participation in KUSM committee activities. Multiple ITV stations are located throughout the medical education building.
Each student has his or her own notebook computer which meets university specifications (e.g., operating system, software). Using a KUSM-issued username/password, students, faculty, and staff have secure high-speed wired and wireless internet connections, maintained by the Kansas City campus. All students have access to curriculum management and virtual microscopy programs. Year 1 and year 2 lectures are digitally recorded, and students may download any lecture to their personal computer shortly after the lecture has been completed. The students can then view the lecture independently. Years 3 and 4 students may also access study guides and didactic materials online. Loaner computers are available in the event that a student's personal computer fails. Finally, all basic science summative exams and clinical clerkship subject exams are computer-based and administered in the testing center on the Salina campus.

\section{Study/Lounge/Storage Space/Call Rooms (Element 5.11)}

Ten dedicated study rooms are located in the medical education building; two to three students may comfortably study in the quiet environment of each of these rooms. At least four other rooms are available as student study rooms most hours of the day. A large lounge is located in the basement of the medical education building. A pool table, table tennis, foosball, cable television, exercise equipment, comfortable furniture, and a small kitchen and dining area are located in this lounge. Adjacent to the lounge is a room with lockers where every student on campus can securely store valuables. Two secure call rooms reserved for student use are located in SRHC.

6. Service Learning (Element 6.6) - "The faculty of a medical school ensure that the medical education program provides sufficient opportunities for, encourages, and supports medical student participation in service-learning and community service activities."

Local community service organizations are given the opportunity to discuss their programs with Salina students. In addition, students are given multiple opportunities (and readily participate) in a variety of community service projects, including checking blood pressures for visitors to the Kansas State Fair, collecting food for the local emergency aid food bank, providing physical exams for indigent students attending summer camp, working at a center for homeless and abused women, entertaining children at a local child care center during holiday parties, and discussing medical school and health care professions at local career fairs. Every student has participated in at least one service project each year, and many students have participated in several. During their year 3 required clerkship in family medicine, all students spend at least one month at Salina Family Healthcare Center, a Federally 
Qualified Healthcare Center providing health care services to a large indigent population.

7. Academic Environments (Element 6.7)—"The faculty of the medical school ensure that medical students have opportunities to learn in academic environments that permit interaction with students enrolled in other health professions, graduate, and professional degree programs and in clinical environments that provide opportunities for interaction with physicians in graduate medical education programs and in continuing medical education programs."

The Smoky Hill Family Practice Residency Program located in Salina, trains four to five PGY1, 2, and 3 family medicine residents per year. Kansas Wesleyan University in Salina offers a BSN in nursing and Kansas State University-Salina offers a social work degree. PharmD students complete part of their training at SRHC, and two PharmD graduates spend a year of residency at SRHC. Salina medical students engage with nursing students, social work students, and pharmacy students and residents as part of formal interprofessional educational activities on campus. Years 1 and 2 students also participate with family medicine residents in bi-monthly supplemental instruction/question group sessions. Years 3 and 4 students interact with family medicine residents, faculty members representing a multitude of disciplines, nurses, social workers, physical therapists, occupational therapists, pharmacists, and chaplains in the normal course of their clinical clerkship rotations. Students are invited to attend meetings of the local medical society (Saline County Medical Society) and also attend and participate in regional (Kansas Academy of Family Practice) and national (American Academy of Family Practice, International Association of Medical Science Educators) meetings.

8. Academic Advising (Element 11.1) — “A medical school has an effective system of academic counseling in place for medical students that integrates the efforts of faculty members, course and clerkship directors, and student affairs staff with its counseling and tutorial services and ensures that medical students can obtain academic counseling from individuals who have no role in making assessment or promotion decisions about them."

The Salina RMC medical education instruction specialist is available to counsel students regarding academic issues, including time management, organizational skills, and test taking skills and strategies. The local instruction specialist works in collaboration with a larger cohort of learning specialists and psychologists on the main campus, who can work with individuals or groups of students via secure videoconferencing or in person. The learning specialist also facilitates study sessions and question groups and assists the main campus in delivering a USMLE step 1 preparation course in Salina.

9. Career Counseling (Element 11.2)_"AA medical school has an effective career advising system in place that integrates the efforts of faculty members, clerkship directors, and student affairs staff to assist medical students in choosing elective courses, evaluating career options, and applying to residency programs."

Students on the Salina RMC are introduced to career options through various means, including: (a) introduction to the online AAMC Careers in Medicine program, (b) required twice-yearly meetings with his or her faculty advisor, (c) formal presentations at student academic society meetings, (d) formal presentations in the year 3 required Issues in Clinical Medicine Course, (e) meetings with the campus dean and campus clerkship director early in year 3, and (f) formal meetings with the Assistant Dean for Student Affairs on the main campus. However, perhaps the most potent influences on a student's choice of a medical career are the physicians and experiences he or she encounters during clinical clerkships.

\section{Provision of MPSE (Element 11.4)}

The Medical Student Performance Evaluation for all students on the Salina campus is prepared and submitted by the Associate Dean for Student Affairs on the main campus in Kansas City. The letter summarizes many comments contained in each student's year 3 clinical clerkship evaluations.

11. Financial Aid/Debt Management Counseling/Student Education Debt (Element 12.1) —“A medical school provides medical students with effective financial aid and debt management counseling and has mechanisms in place to minimize the impact of direct educational expenses (i.e., tuition, fees, books, supplies) on medical student indebtedness."

Tuition at KUSM is identical on all three campuses, $\$ 32$, 523 per year for Kansas residents in academic year 2014 2015. Financial assistance on the Salina campus is managed by the Financial Aid Office on the main campus, although the Salina campus Dean has some input regarding scholarships for Salina students. Sixteen of the first 32 students attending the Salina campus elected to participate in the Kansas Medical Student (KMS) Loan Program, a state-sponsored program covering the cost of medical school tuition and providing the student with a monthly living stipend. The loan is forgiven on a year-for-year basis, if the student eventually establishes a primary care practice in rural and/or underserved Kansas. This program benefits the recipient students, who have a 
substantial portion of their medical school expenses paid for by the state, and the rural communities in Kansas served by these students.

Salina students not receiving KMS loans receive scholarships provided by local individuals and institutions. The average award is $\$ 16,000$ per student yearly. Because of these financial aid programs, student debt on the Salina campus is predicted to be significantly lower than $\$ 167,763$, the mean indebtedness for medical school education for graduates of public institutions in 2014 [9]. The financial aid officer on the main campus also provides debt management information to the Salina students during regularly scheduled ITV meetings, campus visits, and by individual request. Students also attend AAMC-sponsored debt management presentations.

12. Personal Counseling/Well-Being Programs (Element 12.3) - "A medical school has in place an effective system of personal counseling for its medical students that includes programs to promote student well-being and to facilitate their adjustment to the physical and emotional demands of medical education."

Students have timely access to a licensed school counselor on staff and to psychologists and psychiatrists through a local behavioral health clinic; appointments are private and confidential. The identified behavioral health professionals are not involved in the teaching or academic assessment of medical students. Students can be seen by self-referral or can be referred by a member of the RMC faculty or staff. Students may also elect to see behavioral health specialists on the main campus. The Salina campus developed a resiliency program, providing medical students with strategies to deal with the stress and burnout associated with medical school and subsequent professional endeavors. Recreation and physical fitness opportunities are provided in partnership with the local YMCA; memberships are covered by student fees.

13. Student Access to Health Care Services (Element 12.4) - "A medical school provides its medical students with timely access to needed diagnostic, preventative, and therapeutic health services at sites in reasonable proximity to the locations of their required educational experiences and has policies and procedures in place that permit students to be excused from educational experiences to seek needed care."

Student well-being, both physical and mental, is of primary importance, and the main campus has policies and procedures in place regarding release from educational activities to seek health care. Unlike the main campus, there is no student health service on the Salina campus. Timely access to health care has been contracted through a local multimember family medicine group and paid for by student fees. A panel of physicians able to provide routine, preventative, urgent, and emergent care for medical students has been identified. Students may be referred to subspecialty physicians in the community or at tertiary care centers when necessary.

14. Non-Involvement of Providers of Student Health Services in Student Assessment/Location of Student Health Records (Element 12.5)

The health professionals providing health care services to Salina students have no involvement in the academic assessment or promotion of the medical students receiving their services. Student medical records are stored in the office of the SRHC employee health nurse.

15. Student Access to Health and Disability Insurance (Element 12.6)

All students attending any campus of KUSM must have proof of health insurance coverage. KUSM offers a health insurance policy for eligible students. All KUSM students have disability insurance, paid through student fees.

\section{Immunization Guidelines (Element 12.7)}

KUSM sets immunization guidelines for all medical students regardless of campus assignment. SRHC provides necessary student immunizations. Immunizations must be complete before starting medical school classes.

17. Student Exposure Policies/Procedures (Element 12.8)"A medical school has policies in place that effectively address medical student exposure to infectious and environmental hazards..."

The Salina RMC follows the exposure policies and procedures published by SRHC. These policies and procedures mirror those of KUSM. Students are informed of these policies before starting year 1 classes and again before starting year 3 clinical clerkships. SRHC employee health nurses are available to answer specific concerns.

\section{Summary}

Delivering an excellent medical education to all medical students attending KUSM is of paramount importance. Creating an environment that fosters the educational process and providing essential support services are equally important, and are mandated by LCME. These services must be provided regardless of campus location - metropolitan or rural. A student's academic success may be directly correlated with how 
well the institution addresses student support services [10,11]. In developing a RMC, considerable attention must be directed toward developing and implementing a curriculum, recruiting faculty and staff, and constructing adequate medical education facilities; however, an equivalent amount of energy needs to be spent developing essential support services. Developing student support services for a rural medical campus can be more challenging, as local resources may not be as robust as those found in urban areas.

The KUSM main campus deliberately and thoughtfully addresses all elements necessary for a successfully functioning RMC in Salina. Perhaps more importantly, the Salina community is an ideal location for a RMC because of supportive local physicians and health center administration, the diverse medical specialties represented in the community, the wealth of patient encounters and clinical experiences afforded the students, the proximity of a GME program and institutions of higher learning, and extraordinary community backing. The main campus, local medical school leadership, and the community work in concert to provide the necessary elements for an accredited, combined (4 years) RMC. It is apparent that certain issues are best managed on the main campus, some are best handled locally, and others require a hybridization process. The necessity to surmount the issues of adequate financial resources, infrastructure development, faculty, and curriculum implementation are obvious. Guaranteeing RMC safety and security and providing students opportunities for engaging in research, library and IT resources, adequate study space, interactions with other health professionals, academic and career advising, financial aid and debt counseling, and timely access to health care must also be addressed early in the planning process.

Fortunately, SRHC shared KUSM's vision in creating a RMC in Salina and donated a facility ideal for a functional and comfortable medical education building. SRHC continues to support the RMC by paying the school's utility expenses and providing maintenance and custodial services. The Salina RMC is also the beneficiary of SRHC's security services and established safety and exposure policies. Nursing and social work students attending other institutions of higher learning in Salina and the presence of family medicine residents training in Salina provide the medical students opportunities to interact with other health care professionals in training. The RMC is able to quickly identify qualified individuals willing to work for the RMC as counselors or to contract with the RMC to provide health care and mental health services. Finally, the main campus supplies other required student support services, including financial aid and debt management counseling, IT support, library resources, and basic science research opportunities.

The RMC in Salina is unique, given its rural location, small size, and extraordinary community support. KUSM's success in creating a rural RMC in Salina may be partially due to good fortune but is also the product of careful planning and hard work. The Salina RMC works closely with the main campus to avoid duplicating support services best provided in Kansas City, while developing services best handled locally. This strategy decreases the strain on limited financial resources. Other medical schools considering creation of rural RMCs may find the KUSM-Salina model for the delivery of student support services worthy of emulation.

Acknowledgments The authors wish to thank Michael Robinson, $\mathrm{PhD}$, Associate Dean for Basic Sciences, KUSM-Salina, and Giulia Bonaminio, PhD, Associate Dean for Medical Education, KUSMKansas City, for reviewing the manuscript.

Open Access This article is distributed under the terms of the Creative Commons Attribution License which permits any use, distribution, and reproduction in any medium, provided the original author(s) and the source are credited.

\section{References}

1. Association of American Medical Colleges. AAMC statement on the physician workforce. https://www.aamc.org/download/55458/data. Accessed 11 Aug 2014.

2. Association of American Medical Colleges. Results of the 2013 medical school enrollment survey. https://members.aamc.org/eweb/ upload/13-239\%20Enrollment\%20Survey\%20201310.pdf. Accessed 11 Aug 2014.

3. Association of American Medical Colleges. Official list of regional medical campuses (as of September 2014). https://www.aamc.org/ members/grmc/resources/. Accessed 15 Oct 2014.

4. Cheifetz CE, McOwen KS, Gagne P, Wong JL. Regional Medical Campuses: a new classification system. Acad Med. 2014;89(8): 1140-3.

5. American Association of Medical Colleges. U.S. medical school applications and matriculants by school, state of legal residence, and sex, 2013. https://www.aamc.org/download/321442/data/ 2013factstable1.pdf. Accessed 11 Aug 2014.

6. Cathcart-Rake WF, Robinson M, Owings CS, Kennedy M, Paolo A, Chumley H. The birth of a rural medical school-the University of Kansas School of Medicine-Salina experience. Med Sci Educ. 2012;22(4):250-8.

7. Paolo A. Annual curriculum evaluation, year 3-class of 2015. Internal KUMC Report for Phase II Committee; July 2014.

8. Liaison Committee on Medical Education. Functions and structure of a medical school. www.lcme.org/publications/2015-16-functionsand-sturucture-with-appendix.pdf. Accessed 11 Aug 2014.

9. American Association of Medical Colleges. Medical student education: debt, costs, and loan repayment fact card. https://www.aamc. org/download/152968/data/debtfactcard.pdf. Accessed 23 Jan 2015.

10. Sayer M, De Saintonge MC, Evans D, Wood D. Support for students with academic difficulties. Med Educ. 2002;36:643-50.

11. Paul G, Hinman G, Dottl S, Passon J. Academic development: a survey of academic difficulties experienced by medical students and support services provided. Teach Learn Med. 2009;21(3): 254-60. 